\title{
BMJ Open Impact of Universal Credit in North East England: a qualitative study of claimants and support staff
}

\author{
Mandy Cheetham, ${ }^{\oplus 1,2}$ Suzanne Moffatt, ${ }^{2,3}$ Michelle Addison, ${ }^{2,4}$ Alice Wiseman ${ }^{5}$
}

To cite: Cheetham M, Moffatt S, Addison M, et al. Impact of Universal Credit in North East England: a qualitative study of claimants and support staff. BMJ Open 2019;9:e029611. doi:10.1136/ bmjopen-2019-029611

- Prepublication history for this paper is available online. To view these files please visit the journal online (http://dx.doi. org/10.1136/bmjopen-2019029611).

Received 6 February 2019 Revised 23 April 2019 Accepted 10 May 2019

\section{Check for updates}

C Author(s) (or their employer(s)) 2019. Re-use permitted under CC BY-NC. No commercial re-use. See rights and permissions. Published by BMJ.

${ }^{1}$ School of Health and Social Care, Centre for Public Health Research, Teesside University, Middlesbrough, UK

${ }^{2}$ Fuse, The Centre for Translational Research in Public Health, Newcastle upon Tyne, UK ${ }^{3}$ Institute of Health and Society, Newcastle University, Newcastle upon Tyne, UK

${ }^{4}$ Department of Social Sciences, Northumbria University, Newcastle upon Tyne, UK ${ }^{5}$ Public Health Department, Gateshead Council, Gateshead, UK

Correspondence to

Dr Mandy Cheetham; m.cheetham@tees.ac.uk

\section{ABSTRACT}

Objectives To understand the impact of the roll-out of Universal Credit (UC) from the perspectives of claimants and staff supporting them in North East England.

Design Qualitative study comprising interviews and focus groups.

Setting Gateshead and Newcastle, two localities in North East England characterised by high levels of socioeconomic deprivation, where the roll-out of UC started in 2017 as a new way to deliver welfare benefits for the UK working age population.

Participants 33 UC claimants with complex needs, disabilities and health conditions and 37 staff from local government, housing, voluntary and community sector organisations.

Results Participants' accounts of the UC claims process and the consequences of managing on UC are reported; UC negatively impacts on material wellbeing, physical and mental health, social and family lives. UC claimants described the digital claims process as complicated, disorientating, impersonal, hostile and demeaning. Claimants reported being pushed into debt, rent arrears, housing insecurity, fuel and food poverty through UC. System failures, indifference and delays in receipt of UC entitlements exacerbated the difficulties of managing on a low income. The threat of punitive sanctions for failing to meet the enhanced conditionality requirements under UC added to claimant's vulnerabilities and distress. Staff reported concerns for claimants and additional pressures on health services, local government and voluntary and community sector organisations as a result of UC.

Conclusions The findings add considerable detail to emerging evidence of the deleterious effects of UC on vulnerable claimants' health and wellbeing. Our evidence suggests that UC is undermining vulnerable claimants' mental health, increasing the risk of poverty, hardship, destitution and suicidality. Major, evidence-informed revisions are required to improve the design and implementation of UC to prevent further adverse effects before large numbers of people move on to UC, as planned by the UK government.

\section{BACKGROUND}

In April 2013, Universal Credit (UC), a flagship component of the UK government's welfare reforms, was introduced, which radically changed the welfare benefits and tax credits system for people of working age. UC
Strengths and limitations of this study

- Universal Credit (UC) represents a significant change in the UK's welfare system, implemented against a backdrop of prolonged austerity, but research on its impact on vulnerable claimants in particular localities has been limited.

- This qualitative study provides detailed insights into the experiences of claiming and managing on UC among vulnerable people with disabilities, longterm health conditions and complex lives in North East England.

- The main limitation is that the sample does not include UC claimants without complex needs.

- We have no reason to believe that the experiences of vulnerable claimants such as those described in this study would not be replicated elsewhere in the UK.

- The experiences of staff supporting UC claimants concur with those of the claimants themselves, adding to the reliability of the findings.

aims to simplify the benefits system, 'make work pay' and reduce system fraud and error. ${ }^{1}$ Combining six separate welfare benefits into 1 monthly payment to a nominated household member has been beset with difficulties. ${ }^{2} \mathrm{UC}$ has been 'rolled out' incrementally and by December 2018, 1.4 million citizens were claiming UC. When the system is fully operational, just under seven million households will receive UC. ${ }^{3}$

$\mathrm{UC}$ is being implemented against a backdrop of prolonged austerity characterised by 'savage' cuts to public expenditure ${ }^{4}$ that have disproportionate impacts on postindustrial areas with higher levels of unemployment, poverty and welfare receipt. ${ }^{56}$ Research by the Equality and Human Rights Commission (2018) shows that the combined impact of tax, welfare reforms and public sector spending changes are greater for poorer households and households with disabilities. ${ }^{6}$ The cash freeze in most benefit rates, cuts to child tax credit and the continued roll-out of UC have significantly reduced the incomes of 
low-income working-age households, particularly those with children. ${ }^{7}$

Prior to its widespread implementation, aspects of UC that have attracted particular critical attention include tougher conditionality and the ratcheting up of sanctions, ${ }^{89}$ a switch to monthly payments, ${ }^{10}$ reduced entitlements and combined payments to couple claimants, ${ }^{11}$ loss of financial control for women, ${ }^{12}$ the digital administration system ${ }^{13}$ and paying housing costs to recipients rather than directly to landlords. ${ }^{414}$ Perhaps most apprehension about the roll-out of UC has concerned those regarded as vulnerable citizens with complex needs including mental and physical health problems, disabilities, difficulties with language, literacy and online access. ${ }^{15}$ Lone parents are regarded as faring particularly badly under UC. ${ }^{16} 17$

A recent National Audit Office report ${ }^{2}$ on the implementation of UC identified that, despite UC amounting to the most significant change in the UK's welfare system since its inception, the Department for Work and Pensions (DWP) has not measured how many UC claimants are having difficulties because it does not have systematic means of gathering intelligence from delivery partners. ${ }^{2}$ Although the DWP found that 4 out of 10 UC claimants they surveyed were experiencing financial difficulties, ${ }^{1}$ very little research on vulnerable claimants with complex needs has been reported.

In 2017, UC was rolled out in two urban localities, Gateshead (population=200500) and Newcastle (population $=300000$ ) in North East England, where this study was set. According to Indices of Multiple Deprivation (2015), Gateshead is ranked 73rd/326 Local Authorities and Newcastle 53rd/326, where 1 is the most deprived ${ }^{18}$; both areas are among the top $20 \%$ most deprived localities in England..$^{19}$ Child poverty levels are 25\% (Gateshead) and 30\% (Newcastle) compared with the English average of $17 \%$. Unemployment, health inequalities, sickness and disability and premature mortality in Gateshead and Newcastle are considerably higher than the average for England and Wales. ${ }^{20}{ }^{21}$ There is a social gradient in health, whereby those who reside in the $10 \%$ most deprived areas in England have a shorter life expectancy (gap of 7 years for women and 9 years for men) than those who live in the most affluent areas of England. ${ }^{22}$ This gap has widened between 2001 and $2015 .^{23}$ The most deprived communities are seeing no life expectancy gain; prolonged austerity, low paid and precarious work and welfare reforms are regarded as contributing factors. ${ }^{23} 24$

This qualitative study set out to examine the impact of UC on claimants' lives and to investigate the ways in which UC was affecting staff supporting claimants in local government and voluntary and community sector organisations. The research questions were as follows:

- What are the health and social effects of the roll-out of UC in Gateshead and Newcastle?

- What are the benefits and risks of the transition to UC for different groups?
- Whose health and wellbeing are affected, in what ways and what is the wider impact on the claimant, their family and local services?

- What are the implications of the findings?

\section{METHODS}

\section{Recruitment and sampling}

UC claimants were recruited via gatekeepers in Gateshead and Newcastle; a housing company and eight voluntary and community sector organisations, which distributed information about the study and identified potential participants. We did not purposively sample UC claimants with particular vulnerabilities, although the advice and support organisations that acted as gatekeepers are likely to see people who require support making and managing their UC claim. Those who agreed for their details to be passed onto the researchers were contacted either by telephone or by email to establish willingness to participate and, if willing, an interview was arranged. People had the opportunity to ask questions about the study and were asked to provide written consent before participating. Inclusion criteria were as follows: aged 18 years or over; lived, worked or accessed services in Gateshead or Newcastle; had applied for UC; had sufficient understanding of English to participate in an interview and were able to give informed consent. Staff were eligible to take part if they supported people claiming UC in a paid professional capacity by offering advice and guidance. The recruitment period was April to October 2018.

\section{Patient and public involvement}

The need for the study emerged from embedded research undertaken by MC with local community groups in Gateshead, drawing on their priorities and experiences. Keen to explore the potential health and social impact of UC on residents, Gateshead Council commissioned the study. Local stakeholders were involved in the conduct of the study and in dissemination of findings. All participants received a copy of the findings and were invited to comment.

\section{Data collection}

Semistructured interviews were undertaken with UC claimants following a topic guide that covered: experiences of the UC claims process, support received, impact of UC on material circumstances, physical/mental health, family relationships and social networks, employment prospects, views about UC and suggestions for changes to UC. After the interview, demographic details were collected and a £10 shopping voucher was given.

Eleven support staff from the local authority, housing and voluntary and community sector participated in individual interviews, and a further 26 took part in five focus groups. Department of Work and Pension staff were invited, but declined to participate, with no reasons given.

Staff interviews and focus groups followed a topic guide that covered: experiences of supporting people to claim UC, perceived impact of UC on claimants, impact of UC 
on staff, implications of UC for service providers and wider health and social care system. Interviews with claimants were carried out by MC $(n=26)$ and MA $(n=7)$; focus groups and interviews with staff were carried out by MC $(\mathrm{n}=37)$ and $\mathrm{SM}(\mathrm{n}=1)$.

\section{Transcription, data management and analysis}

UC claimant interviews lasted between 25 and $85 \mathrm{~min}$ (average $55 \mathrm{~min}$ ), were digitally recorded and transcribed verbatim. Focus group interviews lasted between 50 and $80 \mathrm{~min}$ (average $65 \mathrm{~min}$ ). Field notes taken immediately after interviews/focus groups were shared among the team. Findings from initial interviews and focus groups were used iteratively to inform subsequent data collection; for example, experiences of job searching emerged so we asked interviewees their views about whether UC helped people find work. Recruitment continued until data saturation was reached. Transcripts were anonymised and checked against recordings to ensure accuracy. Thematic analysis was used $;{ }^{25}$ data management and retrieval was undertaken using Word. Transcripts were read and reread by MC and SM, following which, a coding scheme was developed that reflected emergent themes. The coding scheme captured data relating to (1) the claims process including payment delays, deductions, debt/arrears; (2) the impact of claiming and managing UC on: finances; physical and mental health; family and social life; employment; and on advice and support staff in local government, voluntary and community and health sectors. These themes reflected the issues that participants identified. The coding framework was applied to an initial five interviews, following which the coding frame was revised, agreed and applied to all interviews. The data set was coded, constant comparison used ${ }^{26}$ and the data were interrogated for deviant cases in order to enhance validity and sensitivity.

\section{RESULTS}

The impact of UC on the lives of claimants is described by detailed analysis of the two central themes: (1) the process of claiming $\mathrm{UC}$ and (2) the consequences of managing on UC. Staff supporting UC claimants provide a further perspective that is reported in conjunction with claimants' experiences.

\section{Participant characteristics}

As shown in table 1, claimants who took part included 33 adults, 13 women and 20 men, aged 21-63years. Most (28) were single, five were living with a partner and eight households had dependent children. Most participants (31) were not in paid employment, 2 were employed and 12 were volunteering. The sample of claimants included individuals who had long-term health conditions/disabilities (15), including self-reported mental health problems (20), self-reported learning disabilities (2), cognitive impairment/dementia, sensory impairment; bereavement; recent discharge from hospital; and stoppage of work through ill health. In addition to these issues, the sample also included: lone parents, people in recovery from addiction, veterans, care leavers, ex-offenders, refugees and homeless people. DWP has introduced Universal Support for groups of people it considers vulnerable, including those experiencing, 'mental and physical health issues, life events, poor skills or limitations such as literacy or language comprehension problems ... limited online access or skills, and those who struggle to budget, ${ }^{2}$ but few participants said they had benefitted from this support or from the offer of Alternative Payment Arrangements such as fortnightly payments or housing payments directly to landlords.

\section{Claiming UC}

The UC claims process was experienced as complicated, difficult, demeaning, impersonal and punitive. Aspects of the UC design and function regarded as particularly problematic were its digital-only system, lack of face-toface contact, long delays to speak to DWP helpline staff and in-built delays for payments.

Walk a day in the shoes of someone who is on it...but until then, don't say it's easy, because it's not, not by a long shot ... If you're not au fait with a computer, it can be really a bit daunting (Claimant 6).

The requirement to initiate and manage a UC claim online was difficult for many participants, echoing $\mathrm{DWP}^{1}$ research, which found only $54 \%$ of claimants were able to register a claim unassisted. Poor digital literacy, lack of computer/internetaccess, email address and difficulties verifying identity online added to the stress of completing an application. Research by DWP ${ }^{1}$ found that the process of verifying identity online was one of the most difficult steps for claimants in the registration process.

It's just a bit of a nightmare. I wasn't given any help, any assistance really. (Claimant 7)

Claimants and staff experienced unhelpful delays of between 25 and $80 \mathrm{~min}$ when ringing the UC helpline to speak to an advisor:

You're on the phone and they just put you on hold. There's no human contact. It's automated. (Claimant 26)

There were numerous examples of system errors that could result in serious payment delays. Participants and support staff consistently described how the UC administration process was poor at responding to queries in a timely way. The responsibility to sort errors was felt to be entirely with the claimant, expected to rectify problems arising from inflexibilities and inadequacies within the system and for whom the consequences could be severe. Participants compared UC unfavourably with the previous system in which they were able to deal with benefit administrators face to face or over the phone. Instead, Claimant 7 described how, under the UC system: 
Table 1 Demographic characteristics of UC claimant participants

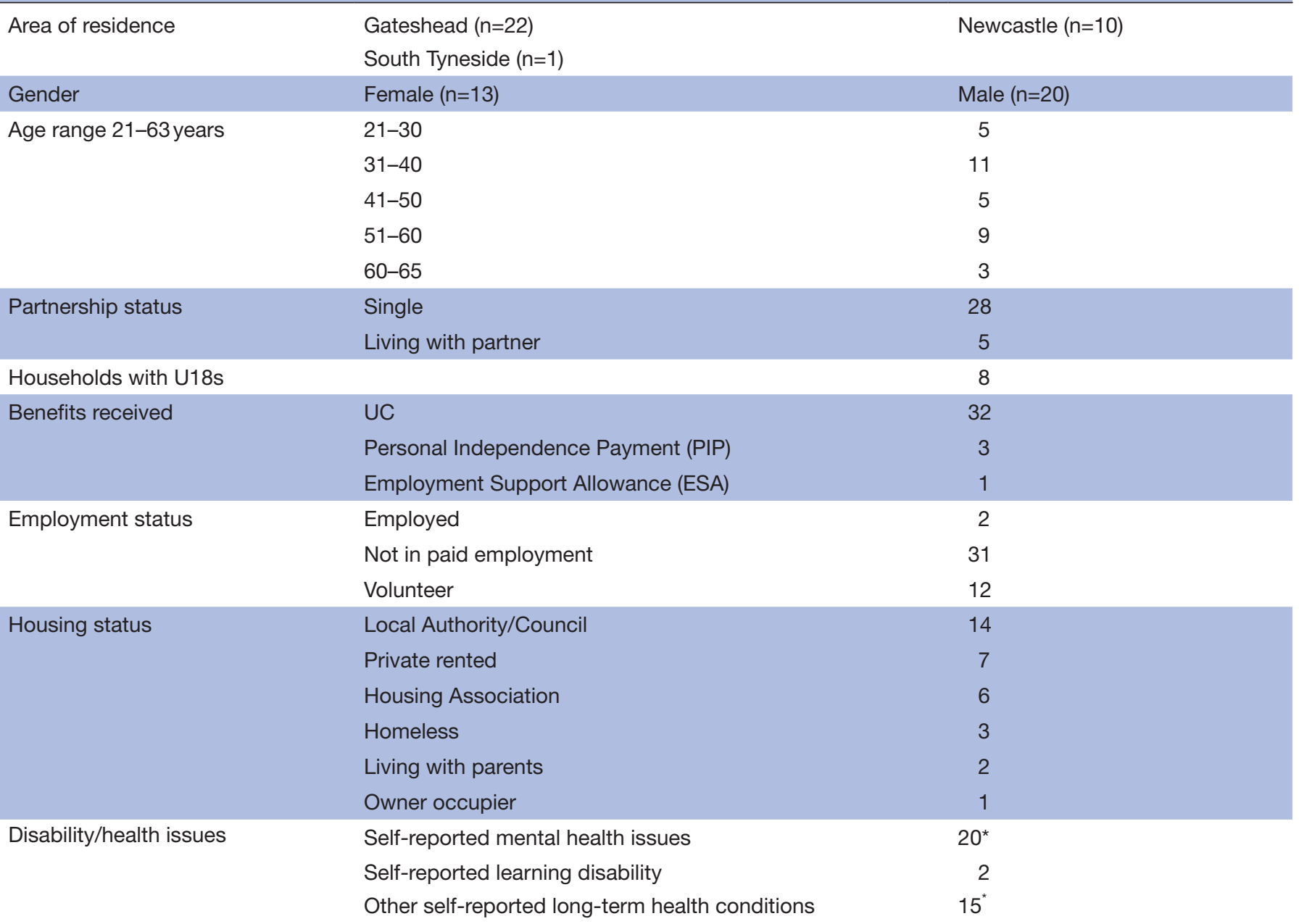

*Some participants reported both mental and physical health conditions.

UC, Universal Credit.

I've had nowt [nothing] but problems ... it's just a bit of a nightmare ... from my experience from starting this claim for Universal Credit, I've been passed from pillar to post three, four, maybe five different people.

A major problem for claimants concerned the in-built 5-week wait for first payment. On average, participants in this study waited 7.5 weeks for their first payment, and this ranged from 5 to 12 weeks. Claimant 15 estimated from personal experience that it was necessary to have, 'a grand's [£1000] worth of savings to survive being put on Universal Credit'. People who could, borrowed from family and friends and 'had to just scrimp' (Claimant 28) to avoid going into debt, rent arrears and suffering serious hardship, which included going without food and utilities. Claimant 2, a single parent, described struggling over winter while waiting for the first payment:

It was so difficult around those 6 weeks [wait for UC payment] ... the council gave me a food voucher but I still needed to buy nappies for the baby. My health visitor brought some food for us, because when she came, it was so cold, she was concerned.
Staff described clients going without basic necessities, observing how some resorted to 'survival crime' in order to manage:

The amount of people who have come in who are starting to get loads of shoplifting charges ... because they're waiting to be paid [UG], their money's been messed up, they've got nothing. (Staff focus group 4)

From January 2018, DWP can offer advance payments of up to a full month's payment, which has to be repaid. However, the repayment mechanism was poorly explained and understood. Some people experienced what they regarded as punitive repayment levels, leaving them with impossibly low incomes:

... they're [government] like loan sharks, because how can you exist on $£ 70$ a week, but it's been cut to $£ 20$ or $£ 30$ ? [due to repayment of advance].

(Claimant 16)

\section{Managing on UC}

Many claimants had difficulty managing on monthly UC payments, which fluctuated unpredictably and were 
affected by administrative errors and delays, punitive deductions and sanctions.

\section{Material Impact}

Materially, some participants were worse off by $£ 100$ per month under UC, including those unable to work due to disability or long-term health problems. Some had lost entitlement to 'Severe Disability Premium' for people with substantial care needs who live alone, which is no longer available under UC, as reported by Claimant 29:

When you feel like, I can't feed myself, I can't pay my electric bill, I can't pay my rent, well, all you can feel is the world collapsing around you. It does a lot of damage, physically and mentally ... there were points where I did think about ending my life, but I managed to fight my feelings, because I knew, at some point, it was going to come right.

Participants described the profound impact of UC delays on debt and rent arrears, resulting in threats of eviction and homelessness for some. Claimant 6 described the stress of receiving a standard letter about arrears from the housing company:

At the time when you get the letter you start panicking ... I felt physically sick to be honest because all of a sudden you start worrying about what's going to happen.

Food insecurity was reported by many participants who were forced to skip meals or use foodbanks. Those with health conditions discussed the difficulties of following nutritional and dietary advice from professionals, because they 'couldn't afford to eat' (Claimant 30).

Claimant 27 lost her job following an accident and struggled to manage on the monthly UC income of $£ 200$. Aware of the financial pressures on her family, she described the stigma of using food banks to which she had previously donated:

It's not right. I shouldn't have to go to my daughters and depend on her for something to eat. It should be the other way round ... It makes you feel so low, especially when you've got to go to the foodbanks. I don't want to be like this for the rest of my life. (Claimant 27)

A minority of participants described sharing their food provisions with their pet, sometimes their sole companion. In one case, a difficult decision was taken to re-home a dog because it was no longer possible to feed them.

\section{Social impact}

The lack of finance and associated strain people experienced impacted on family and social life. There was shame at requiring financial or food assistance from family and friends, many of whom were also surviving on low incomes. Some participants lacked resources for everyday activities that maintained contact with family and friendship networks as described by Claimant 22, who no longer felt able to play a full role as a grandparent:

It has a huge impact. You cannot do things. It's so frustrating. I want to cry sometimes, because, like my grandkids, you know, I cannot give them what I want. (Claimant 22)

Social activity was recommended by health professionals for Claimant 28, who had stopped work for health reasons. He explained this was not possible due to a considerable reduction in income following the transition to UC:

I would put some petrol in my little van and get one of the other older guys, like myself. We used to just go fishing or we'd go to the beach ... I'd go to the pictures and take my granddaughter or my daughter or one of the family ... I don't do it now because it's not economically viable. (Claimant 28)

Surviving on a low income made every day social activities difficult or impossible, thereby increasing the risk of loneliness and social isolation.

\section{Impact on physical and mental health}

Most participants described their perception of a hostile, dysfunctional, uncaring system, which was difficult to navigate. Some felt they were not trusted or believed when they tried to explain their circumstances, as Claimant 1 described:

I ended up being treated for depression and anxiety, anyway, as well as the insomnia, still on medication now. I'm a lot better than I was then. I really was at the lowest ebb that I've ever been in my life I think ... Universal Credit was the straw that broke the camel's back. It really did sort of drag me really, really to a low position, where I don't want to be sort of thrown into again. (Claimant 1)

A number of participants had experienced major life events, such as loss of job or home, bereavement or relationship breakdown, and the UC claims process was felt to add to their difficulties:

It's like insidious brutality, this Universal Credit thing. I don't know who dreamed it up, because on paper I can see some bits of it could be really good. Maybe it's just the way it's being implemented. (Claimant 16)

This claimant described how she had unsuccessfully tried to renegotiate the job searching requirements agreed as part of her claimant commitment, to take account of her housing and health problems:

It's the hoops they make you jump through. They make it really, really difficult and they threaten you with sanctions at every turn. (Claimant 16)

The lack of money due to payment delays and errors compounded the mental health problems of participants. Claimant 11 described how this affected her partner: 
He was in and out of hospital with his depression, like self-harming and that. It was just horrible ... He spoke to the psychiatrist in the hospital. He was like, we've got no money, what's the point, I can't go out, can't see people, can't even eat properly. (Claimant 11)

UC was reported to have caused such distress and loss of hope for the future among six of the research participants, that they had considered suicide. Uncertainty over monthly payments, incomes reduced to the point that basic necessities became unaffordable and a sense that the UC 'system' was unresponsive and obstructive were apparent in these accounts:

I'm not a danger now, but the police have been round because I've been suicidal, that's how bad it's been ... just desperately thinking 'how am I going to eat?' It stemmed from the fact that I had to get a loan from them on top ... and now they take $£ 50$ off my benefits, which leaves me with next to nothing. (Claimant 3)

A number of individuals with health problems were claiming UC after being reassessed as fit for work; a process experienced as extremely distressing, triggering suicidal thoughts:

When I lost my ESA (Employment and Support Allowance), I got to the stage where I was ready to commit suicide. I made an emergency appointment and went to see the doctor and explained how I was feeling ... I had all the tablets at home saved up that I was going to take. (Claimant 30)

\section{Impact on staff supporting UC claimants}

Staff accounts repeatedly reinforced the negative impact of UC on claimants. In addition, adverse effects were reported on staff in local government and the voluntary and community sectors caused by increased workload and the strain of supporting people with complex needs through a UC system not designed to meet their needs.

The significant time staff spent supporting vulnerable clients to manage their UC claims meant that they were less able to provide the support and care they wanted to offer:

It's just never ending. It's just continuous. There is a burnout, I think in a support role, but I think it's going to be shorter now that Universal Credit is having such a huge impact on clients' lives. (Staff 3)

Staff also provided examples of how UC impacts on demand in other services, including in primary and secondary healthcare:

How much pressure is there on the NHS if let's say a sanction saves the DWP $£ 1,000$, how much is that costing the NHS? Is it costing them $£ 10000$ because you have a hospital admission because of it? ... it's very short sighted. (Staff 12)
The deepening impact of cuts in public services, reducing resources, organisational and personal pressures and increasing workload as a result of an 'unworkable and cruel' (Staff 8) UC system were said to be creating additional costs:

... health just spirals out of control because of these wider determinants of health. People are being forced to do things that are actually making their health worse, and then that costs the NHS more, and then they reach crisis point, when actually they weren't in too bad a position when they started. (Staff 9)

Typically, staff anticipated a bleak outlook as the roll-out of UC gathers momentum with increasing numbers of vulnerable claimants being found 'fit for work' and then sanctioned because they cannot cope with the mandatory requirements placed on claimants. Ground down and demoralised by what they saw as the 'nightmare' of the UC roll-out, staff were 'fearful for clients' ahead of the further roll-out of UC, predicting 'the worst is yet to happen' (Staff $4)$. There was little confidence that the UC system could meet the needs of vulnerable people with complex needs:

... if you wanted to devise a system that discriminated against people with learning disabilities, this would be it ... it absolutely particularly discriminates against people with mental health problems and people with learning disabilities. (Staff 8)

\section{DISCUSSION}

This study demonstrates how vulnerable people with complex lives, many of whom have health problems or disabilities, are pushed into debt, rent arrears, fuel and food poverty through $\mathrm{UC}$ and as has been described elsewhere in the UK, exacerbates the 'lived experiences of vulnerability' (p16). ${ }^{27}$ The deleterious consequence of the UC claims process itself, which was experienced as complicated, impersonal and demeaning, is a particularly distressing finding. Participants' accounts demonstrate how the 5 -week payment delay (which in practice ranged from 5 to 12 weeks) exacerbates the difficulties of managing on low incomes. UC was designed with the assumption that most claimants would have enough money to manage over the initial waiting period ${ }^{2}$ or could draw on social or family support, despite UK evidence that in 2018 almost 10 million households had no savings and a further 3.26 million households had savings under $£ 1500$ (\$1955; €1736). ${ }^{28}$

Managing the UC digital claims process caused frustration and confusion and adversely affected claimant's mental health, increasing the possibility of serious selfharm and suicidal ideation, reinforcing other qualitative research on the mental health impact of welfare reform undertaken before UC was rolled out. ${ }^{29}{ }^{30}$ Furthermore, punitive deductions pushed vulnerable claimants into debt and destitution, risk of alcohol and substance use relapse, increasing reliance of foodbanks, family and 
friends. The threat of sanctions for not meeting the mandatory job searching requirements of $\mathrm{UC}^{31}$ and heightened fears of eviction and homelessness combined to seriously destabilise claimants' mental health and emotional wellbeing. UC increased financial and housing insecurity and served to push vulnerable claimants further from the labour market, undermining the intended aim of encouraging people into work. Similar concerns about the implementation of conditionality and the effects of sanctions on claimants have been reported in the largest UK study to date. ${ }^{32}$

The experiences reported by UC claimants and staff in this study echo DWP's own survey of UC claimants, ${ }^{1}$ which reported that older claimants and people with long-term health conditions were faring less well on UC, requiring greater support to register and manage a claim.

It is now well established that being in employment does not equate to being out of poverty ${ }^{33}$; almost $60 \%$ of UK citizens in poverty are in families where someone works. ${ }^{34}$ Rather than providing a safety net, UC is undermining basic rights to a decent standard of living, housing and health at a time of stringent cuts to public services. This is important given the uneven impact of welfare reform in the UK with estimated financial losses higher in older industrial areas such as North East England. ${ }^{35}$ The cumulative impact of UC is hitting hard alongside other welfare reforms, including real terms reduction in benefit income due to welfare 'reform'/retrenchment, alongside rising living costs and wage stagnation.

This study refutes claims of client satisfaction with UC reported by government ${ }^{1}$ and some members of parliament. ${ }^{36}$ The findings show that expert criticism levelled at UC in advance of its implementation ${ }^{837}$ and predictions about the impact of UC on disadvantaged citizens, including disabled people ${ }^{38}$ lone parents ${ }^{16}$ and those with mental health conditions, ${ }^{39}$ have been proved correct. It would appear that the dread anticipated by future claimants is well founded, ${ }^{40}$ exacerbating digital exclusion, ${ }^{41}$ (in) equality ${ }^{12}$ and increasing costs and dissatisfaction. ${ }^{15}$

The consequences of the "burden of welfare reform, 40 on citizens can be seen by the impacts on material circumstances, emotional and social life and health. Between 2009 and 2013, there was a significant increase in self-reported mental health problems in the UK population compared with 2004-2008. ${ }^{42}$ This increase was greater for people with low levels of education, widening inequalities in mental health. ${ }^{42}$ Recent UK research on mental health, austerity and welfare reform has concluded that cuts in social security are impacting on health through a combination of material and psychosocial pathways that include increased financial hardship and chronic stress. ${ }^{29}$ Strong associations between debt, depression, mental illness and suicide were identified in a systematic review. ${ }^{43}$ Increases in self-harm can be a consequence of debt, benefit change and economic hardship associated with austerity. ${ }^{30}$ Fear of benefits being withdrawn, administrative errors and sanctions, identified in this study, have been identified as common drivers of suicidality. ${ }^{44}$
There is an overall acceptance that simplification of the benefits system is a laudable aim. However, the social security system reflects a wide variety of life situations, which means that by its very nature, it will inevitably be complicated. ${ }^{13}$ UC is 'digital by default' as a means of promoting greater flexibility, cost-effectiveness, efficiency and making citizens more responsible for their own claims. Research on fully digital welfare provision is scant, but work in Denmark, with its highly digitalised public administration and welfare system, indicates that "excluded citizens are pushed further to the fringes of the welfare system' (p2), ${ }^{41}$ demonstrating that the use of digital technology can add to existing patterns and mechanisms of exclusion. ${ }^{41}$ In the UK, 'digital assistance' for claiming UC has been outsourced to public libraries and civil society organisations ${ }^{39}$ themselves subjected to public sector funding cuts. Moreover, as has been reported elsewhere ${ }^{45}$ this study found that voluntary and community sector staff are diverted from their core activities and instead required to assist recipients deal with the negative consequences of the benefit system, which can be extremely harsh.

The findings add to a growing body of evidence about the hardships, indignities and financial difficulties experienced by UK citizens receiving state benefits. ${ }^{141140}$ These observations were reinforced by the United Nations Special Rapporteur on extreme poverty and human rights, who described the UK benefit system as 'punitive, callous and inhumane' (p3) during his recent visit to the $\mathrm{UK}^{46}$

\section{Strengths, limitations and implications}

Research on the impact of the roll-out of UC in particular localities is limited. ${ }^{2}$ A key strength of this study is to provide evidence about the impact of UC on vulnerable people with complex lives. Research reported here reinforces findings from a recent study on the impact of $\mathrm{UC}$ on vulnerable people in North West England, ${ }^{27}$ which strengthens the transferability of our findings to similar populations elsewhere in the UK. The inclusion of staff who support claimants provides additional perspectives, which reinforce the findings from claimants. Although claimants with a wide range of life experiences were recruited, the study is limited by not including vulnerable claimants from areas outside North East England and only involving claimants who spoke a good level of English. There is an urgent need for further independent academic research on the impact of UC among disadvantaged groups, including single parents, and those in work with low and fluctuating incomes and self-employed claimants. An updated Equality Impact Assessment, last undertaken in $2011,{ }^{47}$ is necessary. Staff participants indicated the considerable stress and additional workload incurred by UC to local government and the voluntary and community sectors. General practitioners are increasingly concerned about the impact that UC is having on their patients' health and wellbeing, ${ }^{48}$ but also the impact on increased demand for general practitioner (GP) 
appointments, particularly as the UC roll-out process gathers momentum. ${ }^{49}$

Specific changes could be made to the design and implementation of UC, which would make a difference to vulnerable individuals, families and communities. Without major, evidence-informed, revisions, UC threatens to increase levels of poverty, health inequalities, drive the disability-employment gap and change the role of government from 'a line of defence against destitution to becoming an active agent in its creation. ${ }^{50}$

Acknowledgements The authors thank all research participants for taking part. They would also like to acknowledge the contributions of Allison Lawson for administrative support, Emma Gibson from Gateshead Council, Clive Davis and Neil Munslow from Newcastle City Council, Professor Peter Phillimore and Dr Ruth Bell from Newcastle University and reviewers for helpful comments on earlier drafts and colleagues from Gateshead Advice Partnership, Gateshead Council Public Health team and members of the Research Advisory Group: Alison Dunn and Peter van der Graaf.

Contributors MC, AW and SM designed the study. MC, MA and SM undertook data collection. MC and SM undertook data analysis and interpretation. MC and SM drafted the manuscript. All authors subsequently commented on the draft manuscript, revising the content, and approved the final version for publication.

Funding The study was commissioned by Gateshead Council Public Health Team. Additional support from Fuse, the Centre for Translational Research in Public Health and Newcastle University Social Determinants Health theme is gratefully acknowledged. MC, SM and MA are members of Fuse, the Centre for Translational Research in Public Health (www.fuse.ac.uk). Fuse is a collaboration between Durham, Newcastle, Northumbria, Teesside andSunderland Universities . Funding for Fuse comes from the National Institute for Public Health Research (NIHR) School for Public Health Research (sphr.nihr.ac.uk). The views expressed in this paper do not necessarily represent those of the funders. These funders had no role in study design, data collection and analysis, decision to publish or preparation of the manuscript.

Competing interests Co-author AW is Director of Public Health at Gateshead Council and contributed to discussions about the study design and research questions, but did not undertake data collection, analysis or interpretation of the data or report writing. Members of the research advisory group included AW and representatives from Teesside University and Citizens Advice Gateshead, who contributed to discussions about the implications of the findings, and the decision to submit the paper for publication.

Patient consent for publication Not required.

Ethics approval This study was approved by Teesside University Health and Social Care Ethics and Research Governance Committee (ref.009/18) and Newcastle University (ref. 1487/3928). R\&D approval was granted from Gateshead Council.

Provenance and peer review Not commissioned; externally peer reviewed.

Data sharing statement No additional data are available.

Open access This is an open access article distributed in accordance with the Creative Commons Attribution Non Commercial (CC BY-NC 4.0) license, which permits others to distribute, remix, adapt, build upon this work non-commercially, and license their derivative works on different terms, provided the original work is properly cited, appropriate credit is given, any changes made indicated, and the use is non-commercial. See: http://creativecommons.org/licenses/by-nc/4.0/.

\section{REFERENCES}

1. Department for Work and Pensions. Universal Credit full service survey research report 958 Department For Work and Pensions, 2018.

2. National Audit Office. Rolling out Universal Credit. London, 2018.

3. Kennedy S, Keen R. Universal Credit roll-out:2018/19. London: House of Commons Library, 2018.

4. O'Hara M. Austerity bites. Bristol: Policy Press, 2015.

5. Schmuecker K. Universal Credit: a Joseph Rowntree Foundation briefing: Joseph Rowntree Foundation, 2017.
6. Reed $\mathrm{H}$, Portes $\mathrm{J}$. The cumulative impact on living standards of public spending changes Research Report 120: Equality and Human Rights Commission. 2018 www.equalityhumanrights.com (accessed 05 Apr 2019).

7. Hood A, Waters T. The impact of tax and benefit reforms on household incomes. $2017 \mathrm{https} / / / w w w . i f s . o r g . u k / u p l o a d s /$ publications/bns/BN196.pdf (accessed 16 Apr 2019).

8. Spicker P, Ramia G, Farnsworth K, et al. Introducing Universal Credit. In: Social policy review 25: analysis and debate in social policy. Bristol: Policy Press, 2013:3-22.

9. Dwyer P, Wright S. Universal Credit, ubiquitous conditionality and its implications for social citizenship. J Poverty Social Justice 2014;22:27-35.

10. Hartfree $Y$. Universal Credit: the impact of monthly payments on low income households. J Poverty Social Justice 2014;22:15-26.

11. Royston S. Understanding Universal Credit. J Poverty Social Justice 2012;20:69-86.

12. Bennett $F$, Sung $S$. Money matters: using qualitative research for policy influencing on gender and welfare reform. Innovation: The European Journal of Social Science Research 2014;27:5-19.

13. Larkin PM, Credit U. 'Positive Citizenship'and the Working Poor: Squaring the Eternal Circle? Modern Law Review 2018;81:114-31.

14. Hickman P, Kemp PA, Reeve K, et al. The impact of the direct payment of housing benefit: evidence from Great Britain. Hous Stud 2017;32:1105-26.

15. Seddon J, O'Donovan B. The Achilles' heel of scale service design in social security administration: The case of the United Kingdom's Universal Credit. Int Soc Secur Rev 2013;66:1-23.

16. Cain R. Responsibilising recovery: Ione and low-paid parents, Universal Credit and the gendered contradictions of UK welfare reform. British Politics 2016;11:488-507.

17. Rafferty A, Wiggan J. The time-related underemployment of lone parents during welfare reform, recession and austerity: a challenge to in-work conditionality? Soc Policy Adm 2017;51:511-38.

18. Gateshead Council. Indices of deprivation. https://www.gateshead. gov.uk/media/2557/Indices-of-Deprivation-2015-Briefing-forGateshead/pdf/Website-Briefing-IMD-2015-for-Gateshead.pdf?m= 636621580254670000 (accessed 05 Apr 2019).

19. Index of Multiple Deprivation. Index of multiple deprivation. 2015 http://dclgapps.communities.gov.uk/imd/idmap.html (accessed 16 Apr 2019).

20. Whitehead M. Due North: The report of the Inquiry on Health Equity for the North. Liverpool: University of Liverpool and Centre for Local Economic Strategies, 2014.

21. Wiseman A. Inequalities; It never rains but it pours: Annual Report of Gateshead Director of Public Health: Gateshead Council, 2017.

22. Bambra C. Health divides: where you live can kill you. Bristol: Policy Press, 2016.

23. Bennett JE, Pearson-Stuttard J, Kontis V, et al. Contributions of diseases and injuries to widening life expectancy inequalities in England from 2001 to 2016: a population-based analysis of vital registration data. Lancet Public Health 2018;3:e586-e597.

24. Addison M, Kaner E, Johnstone P, et al. Equal North: how can we reduce health inequalities in the North of England? A prioritization exercise with researchers, policymakers and practitioners. J Public Health 2018:1-13.

25. Green J, Thorogood N. Qualitative methods for health research. 4th edn. London: Sage, 2018.

26. Glaser B, Strauss A. The discovery of grounded theory. London: Routledge, 1967.

27. Stinson H. Supporting people? Universal Credit, conditionality and the recalibration of vulnerability. Dwyer $\mathrm{P}$, ed. Dealing with welfare conditionality,. Bristol: The Policy Press, 2019.

28. Money Advice Trust. A decade in debt: how the UK's debt landscape has changed from 2008 to 2018 as seen at National Debtline: Money Advice Trust, 2018.

29. Mattheys K, Warren J, Bambra C. "Treading in sand": A qualitative study of the impact of austerity on inequalities in mental health. Soc Policy Adm 2018;52:1275-89.

30. Barnes MC, Gunnell D, Davies R, et al. Understanding vulnerability to self-harm in times of economic hardship and austerity: a qualitative study. BMJ Open 2016;6:e010131.

31. Department for Work and Pensions. Universal Credit: welfare that works. London: The Stationary Office, 2010.

32. Dwyer PJ. Members of the Welfare Conditionality project team 2018, Final Findings Report: The Welfare Conditionality Project 2013-2018: University of York.

33. Shildrick T, MacDonald R, Scott Webster C, et al. Poverty and Insecurity: Life in low-pay, No-pay Britain. Bristol: Policy Press, 2012.

34. Social Metrics Commission. A new measure of poverty for the UK, 2018. 
35. Beatty C, Fothergill S. Hitting the poorest places hardest: the local and regional impact of welfare reform: Centre For Regional Economic and Social Research: Sheffield Hallam University, 2017.

36. UK Parliament Hansard House of Commons. UK Parliament Hansard House of Commons volume 647 Universal Credit, 2018.

37. Sainsbury R. Universal Credit: the story so far. J Poverty Social Justice 2014;22:11-13.

38. Dwyer $\mathrm{P}$, Jones $\mathrm{K}$, McNeill J, et al. First wave findings: disability and conditionality. 2016 www.welfareconditionality.ac.uk

39. House of Commons Work and Pensions Committee. Oral evidence: Universal Credit roll out, HC 336, questions 665-724: House of Commons, 2018.

40. Patrick R. For whose benefit? The everyday realities of welfare reform. Bristol: Policy Press, 2017.

41. Schou J, Pors AS. Digital by default? A qualitative study of exclusion in digitalised welfare. Soc Policy Adm 2018;2018:1-14.

42. Barr B, Kinderman P, Whitehead M. Trends in mental health inequalities in England during a period of recession, austerity and welfare reform 2004 to 2013. Soc Sci Med 2015;147:324-31.

43. Richardson T, Elliott P, Roberts R. The relationship between personal unsecured debt and mental and physical health: a systematic review and meta-analysis. Clin Psychol Rev 2013;33:1148-62.

44. Bond N, Holkar M. A silent killer; breaking the bond between financial difficulty and suicide. Money and Mental Health Policy Institute London 2018.

45. Jones K. No strings attached? An exploration of employment support services offered by third sector homelessness organisations. Dwyer P, ed. Dealing with welfare conditionality. Bristol: The Policy Press, 2019:91-118.

46. Alston P. Statement on visit to the United Kingdom. London: Office of the United Nations High Commissioner for Human Rights, 2018.

47. Department for Work and Pensions. Welfare reform bill Universal Credit equality impact assessment. London: The Stationary Office, 2012.

48. Arie S. UK. Doctors' concerns over Universal Credit are mounting. BMJ 2018:k5131.

49. Walton E. A truth universally acknowledged: moving to Universal Credit leads to large debt and poor mental health. Br J Gen Pract 2018;68:577.

50. Field F. 'Hitting Rock Bottom'. In: Ives E, Soodeen F, Burning Britain? Great Britain: Bright Blue \& Joseph Rowntree Foundation, 2018:30. 